\title{
Analisis Pengaruh Service Failure terhadap Kepuasan Pelanggan Melalui Service Recovery pada Pelanggan OYO di Kota Medan
}

\author{
Muhammad Hajar Haitami \\ muhammadhajar23@gmail.com \\ Universitas Sumatera Utara \\ Syafrizal Helmi Situmorang \\ Shelmi09@gmail.com \\ Universitas Sumatera Utara
}

\begin{abstract}
The purpose of this study was to determine the influence of service failure on customer satisfaction through service recovery for OYO customers in Medan City. This type of research is associative research. The population in this study were customers of OYO in Medan City. The sample in this study were 150 customers of OYO in Medan City who have complained. The analytical method used in this study is descriptive analysis method and path analysis that was proceseed statistically with SPSS for windows software. The result of the mediation test show that service recovery significantly mediates the relationship between service failure and customer satisfaction. The result of path analysis, the service failure variable has a negative and significant influence on customer satisfaction, the service failure variable has a negative and significant influence on service recovery, and the service recovery variable has a positive and significant influence on customer satisfaction. Based on the size of the Adjusted R-square, it can be seen that the service failure and service recovery variables simultaneously influence the customer satisfaction of $49,5 \%$ while the remaining $50,5 \%$ is influenced by other factors outside the variables studied.
\end{abstract}

Keywords: Service Failure, Service Recovery, Customer Satisfaction, Path Analysis

\section{Pendahuluan}

Fenomena kebangkitan generasi millenial menjadi sebuah peluang usaha bisnis baru dengan menyediakan toko online sebagai bagian dari e-commerce. E-commerce merupakan suatu kumpulan yang dinamis antara teknologi, aplikasi, dan proses bisnis yang menghubungkan perusahaan, konsumen, dan komunitas tertentu melalui transaksi elektronik. Menurut (Laudon \& Traver 2017), E-commerce didefinisikan sebagai transaksi komersial yang melibatkan pertukaran nilai yang dilakukan melalui atau menggunakan tekonologi digital antara individu. Media e-commerce melibatkan penggunaan internet, world wide web, dan aplikasi atau browser pada perangkat seluler atau mobile untuk bertransaksi bisnis. Platform mobile adalah pengembangan terbaru dalam infrastruktur Internet dari berbagai perangkat mobile seperti smartphone dan tablet melalui jaringan nirkabel (wifi) atau layanan telepon seluler. Pada awal berkembangnya e-commerce, satu-satunya media digital adalah web browser, namun saat ini media yang lebih banyak digunakan adalah melalui aplikasi mobile (Laudon dan Traver, 2017). E-commmerce memungkinkan transaksi jual beli dilakukan secara online dari sudut tempat manapun. E-commerce menjadi trend yang sedang berkembang dengan menciptakan peluang baru bagi perusahaan dan konsumen dengan 
jumlah pendapatannya yang selalu meningkat dari tahun ke tahun. Perusahaan semakin menyadari fakta tersebut dan mereka sering menggunakan media e-commerce dalam strategi bisnis sebagai saluran distribusi.

Menurut riset yang dilakukan oleh IDN Research (2019), dalam laporannya yang bertajuk Indonesia Millenial Report 2019, empat dari sepuluh millenial traveling ke luar kota atau ke luar negeri setiap tahunnya. Banyaknya orang yang saling berpergian dari tempat yang jauh membuat jasa ini menjadi sangat penting. Saat ini perusahaan jasa penginapan (Hotel) jumlahnya cukup banyak dari perusahaan yang berskala kecil sampai perusahaan asing berskala besar yang memiliki kantor cabang di Indonesia khususnya Provinsi Sumatera Utara. Dari beberapa perusahaan jasa penginapan (Hotel) yang dikenal oleh masyarakat, PT OYO Rooms Indonesia (OYO) merupakan salah satu penyedia jasa penginapan (Hotel) berbasis virtual hotel operator (VHO) yang cukup terkenal. OYO berbasis reservasi dengan menggunakan aplikasi pada telepon pintar atau gadget yang tersambung dengan internet sehingga wisatawan dapat langsung terhubung pada website resmi OYO.

Meskipun PT OYO Rooms Indonesia (OYO) di Indonesia saat ini sudah berkembang pesat, OYO pernah mengalami kegagalan dalam melayani pelanggannya seperti pemesanan hotel dibatalkan sepihak, fasilitas AC bermasalah, proses refund yang lama, dll. Terkait kegagalan pelayanan yang diberikan PT OYO Rooms Indonesia (OYO), pelanggan dapat menyampaikan komplain melalui Contact Center OYO Indonesia yang disediakan oleh PT OYO Rooms Indonesia (OYO), baik dalam bentuk nomor layanan pelanggan via sambungan telepon, website resmi perusahaan jasa penginapan maupun dalam bentuk kantor penyedia layanan pelanggan untuk interaksi langsung dengan pihak perusahaan.

Tetapi ada juga pelanggan yang mengalami ketidakpuasan terhadap layanan yang diberikan oleh penyedia jasa dalam penyampaian komplainnya diluapkan dimedia sosial. Hal tersebut dilakukan oleh PT OYO Rooms Indonesia (OYO), sebagai upaya untuk meningkatkan kualitas pelayanan agar pelanggan merasa puas. Oleh karena itu, PT OYO Rooms Indonesia (OYO) perlu melakukan monitor pelaksanaan service recovery untuk mengetahui seberapa tuntas masalah atau kegagalan layanan dapat diselesaikan sehingga dapat menciptakan kepuasan bagi pelanggannya.

Berdasarkan latar belakang masalah diatas maka dapat dirumuskan permasalahan penelitian sebagai berikut:

1. Apakah service failure berpengaruh secara parsial terhadap kepuasan pelanggan PT OYO Rooms Indonesia (OYO) di Kota Medan?

2. Apakah service failure berpengaruh secara parsial terhadap service recovery PT OYO Rooms Indonesia (OYO) di Kota Medan?

3. Apakah service recovery berpengaruh secara parsial terhadap kepuasan pelanggan PT OYO Rooms Indonesia (OYO) di Kota Medan?

4. Apakah service failure secara tidak langung berpengaruh terhadap kepuasan pelanggan melalui service recovery PT OYO Rooms Indonesia (OYO) di Kota Medan?

5. Apakah service failure berpengaruh secara simultan terhadap kepuasan pelanggan melalui service recovery PT OYO Rooms Indonesia (OYO) di Kota Medan?

Dengan berkembangnya situs akomodasi yang berbasis virtual hotel operator (VHO) di Indonesia. PT OYO Rooms Indonesia sebagai salah satu situs akomodasi yang berbasis virtual hotel operator (VHO) yang cukup populer di kalangan generasi millenial perlu memperhatikan standar pelayanan terhadap konsumen agar meminimalisir terjadinya 
kegagalan layanan (service failure). Oleh karena itu diperlukan strategi pemulihan layanan (service recovery) efektif yang dilakukan oleh PT OYO Rooms Indonesia (OYO) agar dapat terus bersaing dengan kompetitornya. Peneliti ingin melihat ada atau tidaknya pengaruh service failure terhadap kepuasan pelanggan melalui service recovery yang dilakukan oleh PT OYO Rooms Indonesia khususnya pada pelanggan di Kota Medan. Service recovery mungkin akan berhasil memperbaiki ketidakpuasan pelanggan akibat terjadinya kegagalan layanan namun bergantung pada penerapan dan jaminan yang diberikan oleh PT OYO Rooms Indonesia kepada pelanggannya.

\section{Landasan Teori dan Pengembangan Hipotesis}

\section{Service Failure}

Kegagalan layanan (service failure) adalah segala jenis kesalahan, kekurangan atau masalah yang terjadi selama penyediaan layanan. Penyebab kegagalan pelayanan bergantung pada faktor individual dan situasional, serta pemahaman secara serius atas kegagalan sebagai faktor yang kritis untuk memilih strategi pemulihan yang tepat (Situmorang \& Mulyono 2019). Kegagalan layanan dari sudut pandang pelanggan telah didefinisikan sebagai "kesalahan atau kesalahan yang timbul selama pemberian layanan, menyebabkan ketidakpuasan (Situmorang \& Mulyono 2019).

Menurut Situmorang \& Mulyono (2019), empat sumber dari service failure, yaitu: layanan (layanan yang tidak tersedia, harga layanan keliru dan layanan yang terlalu terlambat, konsumen terlalu lama menunggu, antrean terlalu panjang), penyedia jasa (tindakan dan perilaku karyawan yang tidak sepatutnya, seperti tidak sopan, kasar, bad mood) hal-hal yang diluar kendali penyedia jasa (faktor lingkungan non-manusia seperti hujan, badai dan perilaku organisasi lain (listrik, air, jaringan) dan pelanggan (pelanggan sendiri dan pelanggan lain).

\section{Service Recovery}

Pemulihan layanan didefinisikan sebagai tindakan spesifik yang perlu dilakukan oleh organisasi untuk memastikan bahwa pelanggan mendapatkan solusi setelah terjadi kegagalan pelayanan yang menyebabkan mereka kecewa atau tidak puas. Pemulihan layanan dilakukan untuk mengimbangi reaksi negatif pelanggan terhadap kegagalan layanan (Situmorang \& Mulyono 2019). Setiap kali terjadi kegagalan layanan, orang berharap diperlakukan dengan adil. Namun, penelitian telah menunjukkan bahwa banyak pelanggan merasa bahwa mereka tidak diperlakukan secara adil atau tidak diberikan kompensasi yang memadai. Ketika ini terjadi, reaksi mereka cenderung langsung, emosional, dan bertahan lama. Sebaliknya, hasil yang dianggap adil memiliki dampak positif pada kepuasan pelanggan (Lovelock \& Wirtz 2018).

Menurut Farticia \& Priadi (2018), Service recovery secara umum dapat diwujudkan dengan tiga cara pokok:

1. Distributive Justice

Atribut yang memfokuskan pada hasil dari penyelesaian service recovery, misalnya usaha apa yang dilakukan perusahaan untuk menangani keluhan konsumen ketika perusahaan melakukan kesalahan, meskipun perusahaan harus mengeluarkan biaya yang besar sebagai pengganti kerugian. Distributive justice dapat diwujudkan dengan need, equity, equality.

2. $\quad$ Procedural Justice

Atribut yang memfokuskan pada keadilan yang seharusnya diterima oleh konsumen ketika mengajukan keluhan sesuai dengan aturan dan kebijakan yang telah ditetapkan 
perusahaan. Procedural justice meliputi process control, decission control, accesibility, timing, flexibility.

3. Interactional Justice

Atribut yang memfokuskan pada kelakuan ataurespon yang ditujukan oleh perusahaan

ketika berhadapan dengan konsumen yang mengajukan komplain. Interactional justice meliputi explanation, honesty, politeness, effort, emphaty.

\section{Kepuasan Pelanggan}

Definisi kepuasan pelanggan menurut Kotler \& Amstrong (2015) ialah perasaan senang atau kecewa yang muncul setelah membandingkan kinerja (hasil) produk yang dipikirkan terhadap kinerja (atau hasil) yang diharapkan. Pelanggan yang sangat tidak puas dapat berubah menjadi "teroris"bagi penyedia layanan dengan menyebarkan kata-kata negative dari mulut ke mulut dalam kelimpahan (Lovelock \& Wirtz 2018).

Menurut Gunawan et al (2019), kepuasan konsumen memiliki alat ukur atau indikator meliputi fulfillment, pleasure, ambivalence.

\section{Kerangka Konseptual}

Dalam penelitian kuantitaf, kerangka berpikir merupakSian model konseptual tentang bagaimana teori berhubungan dengan berbagai faktor yang telah diidentifikasi sebagai masalah yang penting (Sugiyono 2019). Kerangka konseptual menggambarkan hubungan dari variabel independen yaitu Service Failure $(X)$ dengan variabel dependen yaitu Kepuasan Pelanggan (Y) yang dimediasi oleh variabel intervening yaitu Service Recovery (Z).

1. Hubungan service failure terhadap kepuasan pelanggan

Kegagalan layanan (service failure) adalah segala jenis kesalahan, kekurangan atau masalah yang terjadi selama penyediaan layanan. Penyebab kegagalan pelayanan bergantung pada faktor individual dan situasional, serta pemahaman secara serius atas kegagalan sebagai faktor yang kritis untuk memilih strategi pemulihan yang tepat (Situmorang \& Mulyono 2019). Kegagalan layanan dari sudut pandang pelanggan telah didefinisikan sebagai "kesalahan atau kesalahan yang timbul selama pemberian layanan, menyebabkan ketidakpuasan pelanggan (Situmorang \& Mulyono 2019).

2. Hubungan service failure terhadap service recovery.

Kegagalan layanan dari sudut pandang pelanggan telah didefinisikan sebagai "kesalahan atau kesalahan yang timbul selama pemberian layanan, menyebabkan ketidakpuasan (Situmorang \& Mulyono 2019). Semakin tinggi tingkat kegagalan pelayanan yang dialami oleh pelanggan, semakin sulit bagi perusahaan untuk melakukan service recovery. Secara garis besar masalah-masalah yang dihadapi setiap perusahaan bisa ditelusuri dari tiga sumber utama yakni dikarenakan oleh perusahaan (janji yang berlebihan), karyawan (kasar, cuek, tidak sopan), pelanggan (tidak mengikuti instruksi atau petunjuk).

3. Hubungan service recovery terhadap kepuasan pelanggan.

Pemulihan layanan didefinisikan sebagai tindakan spesifik yang perlu dilakukan oleh organisasi untuk memastikan bahwa pelanggan mendapatkan solusi setelah terjadi kegagalan pelayanan yang menyebabkan mereka kecewa atau tidak puas. Pemulihan layanan dilakukan untuk mengimbangi reaksi negatif pelanggan terhadap kegagalan layanan (Situmorang \& Mulyono 2019). Setiap kali terjadi kegagalan layanan, orang 
berharap diperlakukan dengan adil. Namun, penelitian telah menunjukkan bahwa banyak pelanggan merasa bahwa mereka tidak diperlakukan secara adil atau tidak diberikan kompensasi yang memadai. Ketika ini terjadi, reaksi mereka cenderung langsung, emosional, dan bertahan lama. Sebaliknya, hasil yang dianggap adil memiliki dampak positif pada kepuasan pelanggan (Lovelock \& Wirtz 2018).

Berdasarkan kajian teori dan tinjauan diatas, maka dapat dikembangkan kerangka pikir penelitian sebagai berikut:

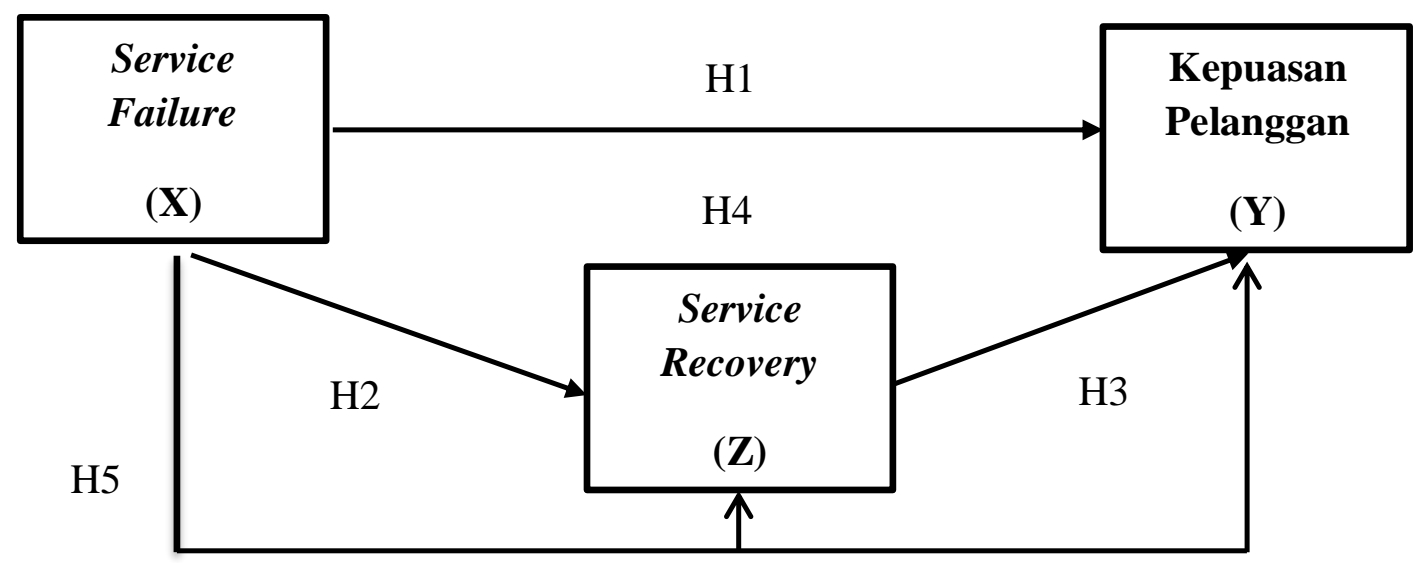

Gambar 1 : Kerangka Konseptual

Berdasarkan rumusan masalah dan kerangka konseptual yang telah dikemukakan diatas maka hipotesis sementara dalam penelitian ini adalah sebagai berikut:

H1 : Service failure berpengaruh negatif dan signifikan terhadap kepuasan pelanggan PT OYO Rooms Indonesia (OYO) di Kota Medan.

$\mathrm{H} 2$ : Service failure berpengaruh negatif dan signifikan terhadap service recovery $\mathrm{PT}$ OYO Rooms Indonesia (OYO) di Kota Medan.

H3 : Service recovery berpengaruh positif dan signifikan terhadap kepuasan pelanggan PT OYO Rooms Indonesia (OYO) di Kota Medan.

H4 : Service failure berpengaruh tidak langsung dan signifikan terhadap kepuasan pelanggan melalui service recovery PT OYO Rooms Indonesia (OYO) di Kota Medan.

H5 : Service failure berpengaruh secara serempak dan signifikan terhadap kepuasan pelanggan melalui service recovery PT OYO Rooms Indonesia (OYO) di Kota Medan.

\section{Metode Penelitian}

Penelitian ini dilakukan mulai dari bulan Juni s.d. Juli 2020 melalui pembagian angket kuesioner pada pelanggan PT OYO Rooms Indonesia (OYO) di Kota Medan yang pernah melakukan komplain. Agar tujuan penelitian dapat lebih terarah dan terfokus, maka dilakukan pembatasan-pembatasan dalam variabel yang diteliti. Penilitian ini menggunakan tiga variabel yaitu:

1. Variabel Terikat (dependent variable) yaitu variabel yang dipengaruhi atau yang menjadi akibat karena adanya variabel bebas (Sugiyono 2017). Variabel dependen dalam penelitian ini adalah Kepuasan Pelanggan (Y).

2. Variabel Bebas (independent variable) yaitu variabel yang mempengaruhi atau yang menjadi sebab perubahan atau timbulnya variabel dependen (Sugiyono 2017).Variabel independen dalam penelitian ini adalah Service Failure (X). 
3. Variabel Intervening yaitu variabel yang secara teoritis mempengaruhi hubungan antara variabel independen dengan dependen menjadi hubungan yang tidak langsung dan tidak dapat diamati dan diukur (Sugiyono 2017)Variabel intervening dalam penelitian ini ada Service Recovery (Z).

Metode pengumpulan data yang digunakan dalam penelitian ini adalah data primer dan data sekunder yang diperoleh melalui studi dokumentasi dan daftar pertanyaan yang pengukurannya menggunakan skala likert.

Uji validitas dan uji realibilitas dilakukan terhadap 30 responden diluar sampel. Suatu pernyataan dikatakan valid apabila nilai $r$ hitung $>r$ tabel. Diketahui seluruh nilai $r$ hitung $>r$ tabel (0.361). Sehingga disimpulkan seluruh pernyataan pada variabel service failure, service recovery, dan kepuasan pelanggan telah valid.

Uji reliabilitas dilakukan untuk menunjukkan sejauh mana, metode yang digunakan dalam pengujian reliabilitas ini adalah menggunakan Cronbach Alpha dengan kriteria pengambilan keputusan menurut Hair et al (2013), yaitu jika koefisien Cronbach Alpha>0.50 maka kuesioner dinyatakan sudah memuaskan (reliable). Diketahui bahwa seluruh nilai Cronbach Alpha pada variabel service failure, service recovery, dan kepuasan pelanggan adalah 0.581, 0.888, 0.748 lebih besar dari 0.50, sehingga kuesioner telah memuaskan (reliable).

Tujuan utama pemberian definisi operasional adalah suatu definisi yang diberikan pada suatu variabel dengan cara memberikan arti atau menspesifikasikan kegiatan, ataupun memberikan suatu operasional yang diperlukan untuk mengukur variabel tersebut.

Tabel 1

Operasionalisasi Variabel

\begin{tabular}{|c|c|c|c|}
\hline Variabel & Definisi Operasional & Indikator & Skala \\
\hline $\begin{array}{c}\text { Service Failure } \\
\text { (X) }\end{array}$ & $\begin{array}{l}\text { Service failure adalah segala } \\
\text { jenis kesalahan, kekurangan } \\
\text { atau masalah yang terjadi } \\
\text { selama penyediaan layanan } \\
\text { kepada pelanggan OYO. }\end{array}$ & $\begin{array}{ll}\text { 1. } & \text { Janji Perusahaan } \\
\text { 2. } & \text { Perilaku Karyawan } \\
\text { 3. } & \text { Pelanggan tidak } \\
& \text { mengikuti } \\
& \text { instruksi. }\end{array}$ & Likert \\
\hline $\begin{array}{c}\text { Service } \\
\text { Recovery }(\mathrm{Z})\end{array}$ & $\begin{array}{l}\text { Service Recovery adalah } \\
\text { tindakan spesifik yang } \\
\text { dilakukan oleh OYO untuk } \\
\text { memastikan bahwa pelanggan } \\
\text { mendapatkan solusi setelah } \\
\text { terjadi kegagalan pelayanan } \\
\text { yang menyebabkan mereka } \\
\text { kecewa atau tidak puas. }\end{array}$ & $\begin{array}{ll}\text { 1. } & \text { Need } \\
\text { 2. } & \text { Equity } \\
\text { 3. } & \text { Equality } \\
\text { 4. } & \text { Process Control } \\
\text { 5. } & \text { Decission Control } \\
\text { 6. } & \text { Accesibiltity } \\
\text { 7. } & \text { Timing/Speed } \\
\text { 8. } & \text { Flexibelity } \\
\text { 9. } & \text { Explanation } \\
\text { 10. } & \text { Honesty } \\
\text { 11. } & \text { Politeness } \\
\text { 12. } & \text { Effort } \\
\text { 13. } & \text { Emphaty }\end{array}$ & Likert \\
\hline
\end{tabular}


INOBIS: Jurnal Inovasi Bisnis dan Manajemen Indonesia

Volume 02, Nomor 02, Maret 2019

Muhammad Hajar Haitami, Syafrizal Helmi Situmorang

\begin{tabular}{|c|l|l|l|}
\hline Kepuasan & Kepuasan Pelanggan adalah & 1. Fulfillment & Likert \\
Pelanggan (Y) & tingkat perasaan pelanggan OYO & 2. Pleasure & \\
& setelah membandingkan (kinerja & 3. Ambivalence & \\
& atau hasil) yang dirasakan & & \\
& dibandingkan dengan harapannya. & & \\
\hline
\end{tabular}

Sumber: Berbagai Literatur dan Penelitian Terdahulu

Metode analisis yang digunakan dalam penelitian ini adalah metode analisis deskriptif dan analisis jalur (path analysis) yang diukur dengan sekala pengukuran likert oleh (Sugiyono 2016) dan diolah dengan software SPSS for windows. Metode sampling yang digunakan adalah metode purposive sampling dengan menggunakan rumus Hair et al (2010) dimana jumlah indikator x 5 yaitu 19 × $8=152$. Pada penelitian ini jumlah sampel 150 responden yang dirasakan sudah cukup untuk mewakili populasi.

\section{Hasil Penelitian}

\section{Analisis Deskriptif Variabel}

Distribusi Jawaban Responden Terhadap Variabel Service Failure (X), Service Recovery (Z) dan Kepuasan Pelanggan (Y).

Tabel 2. Distribusi Frekuensi dan Persentase Berdasarkan Jawaban Responden utuk Variabel Service Failure (X), Service Recovery (Z) dan Kepuasan Pelanggan (Y)

\begin{tabular}{|c|c|c|}
\hline Variabel & Pernyataan & Rata-Rata \\
\hline $\begin{array}{l}\text { Service } \\
\text { Failure (X) }\end{array}$ & $\begin{array}{l}\text { 1. Janji yang berlebihan dalam hal fasilitas sehingga tidak sesuai dengan ekspektasi } \\
\text { pelanggan } \\
\text { 2. Petugas/karyawan OYO menunjukkan sikap buruk seperti kasar, cuek, tidak sopan, } \\
\text { dll terhadap pelanggan } \\
\text { 3. Pelanggan OYO membuat keributan sehingga membuat pelanggan yang lain tidak } \\
\text { nyaman }\end{array}$ & $\begin{array}{ll}1 . & 3.23 \\
\text { 2. } & 3.23 \\
\text { 3. } & 3.20\end{array}$ \\
\hline $\begin{array}{l}\text { Service } \\
\text { Recovery }(\mathrm{Z})\end{array}$ & $\begin{array}{l}\text { 1. OYO memberikan solusi sesuai dengan yang dibutuhkan pelanggan } \\
\text { 2. OYO memberikan kompensasi yang wajar kepada pelanggan } \\
\text { 3. Kompensasi yang diberikan OYO sebanding dengan kerugian pelanggan } \\
\text { 4. OYO memberikan proses penanganan keluhan yang baik mulai dari keluhan yang } \\
\text { sederhana hingga keluhan yang kompleks } \\
\text { 5. OYO memberikan keputusan yang tepat terhadap setiap keluhan } \\
\text { 6. OYO mempermudah akses kepada pelanggan untuk menyampaikan keluhan } \\
\text { 7. OYO menangani keluhan pelanggan dengan cepat } \\
\text { 8. OYO bersikap fleksibel terhadap prosedur dalam menangani keluhan pelanggan } \\
\text { 9esuai dengan situasi dan kondisi pada saat itu } \\
\text { 9. OYO memberikan penjelasan dengan baik terhadap konsumen mengenai } \\
\text { 10. OYO dengan jujur mengakui kegagalan layanan yang dialami pelanggan } \\
\text { 11. OYO sopan dan menghargai konsumen dalam menangani keluhan pelanggan } \\
\text { 12. OYO berusaha secara maksimal dalam menemukan solusi untuk menangani } \\
\text { keluhan pelanggan } \\
\text { 13. OYO memberikan perhatian dan peduli terhadap pelanggan serta memahami apa } \\
\text { yang diinginkan pelanggan }\end{array}$ & $\begin{array}{ll}1 . & 3.19 \\
\text { 2. } & 3.27 \\
\text { 3. } & 3.62 \\
\text { 4. } & 3.47 \\
\text { 5. } & 3.38 \\
\text { 6. } & 3.28 \\
\text { 7. } & 3.40 \\
\text { 8. } & 3.51 \\
\text { 9. } & 3.49 \\
\text { 10. } & 3.35 \\
\text { 11. } & 3.49 \\
\text { 12. } & 3.29 \\
\text { 13. } & 3.47\end{array}$ \\
\hline $\begin{array}{l}\text { Kepuasan } \\
\text { Pelanggan (Y) }\end{array}$ & 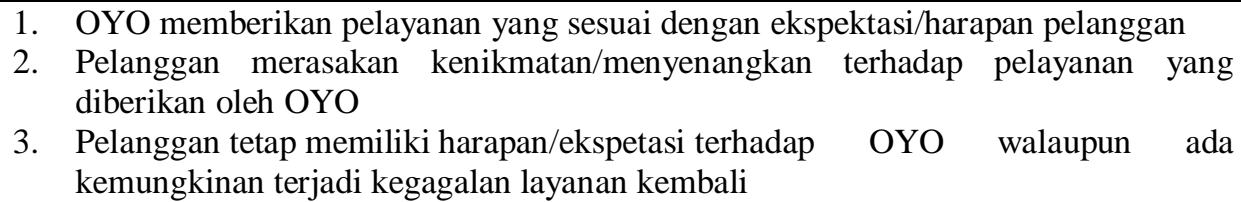 & $\begin{array}{ll}1 . & 3.44 \\
\text { 2. } & 3.39 \\
\text { 3. } & 3.33\end{array}$ \\
\hline
\end{tabular}

Sumber: Data diolah 2020 
Berdasarkan tabel 2 dapat dilihat bahwa variabel service failure $(\mathrm{X})$ pada pernyataan ke-1 (OYO membuat janji yang berlebihan dalam hal fasilitas sehingga tidak sesuai dengan ekspektasi pelanggan) dengan nilai rata-rata sebesar 3.23. Dari data tersebut dapat disimpulkan bahwa pelanggan yang melakukan komplain pada OYO di Kota Medan lebih banyak menyatakan setuju terhadap pernyataan ke-1 variabel service failure (X). Hal ini disebabkan oleh service failure yang dialami pelanggan seperti mendapatkan kamar yang tidak sesuai dengan yang dipesan, kamar kotor, tidak tersedia WIFI seperti yang dijanjikan, pendingin ruangan yang rusak, toilet bau dan kamar tidak dibersihkan saat pagi hari. Variabel service recovery $(\mathrm{Z})$ pada pernyataan ke-3 (kompensasi yang diberikan OYO sebanding dengan kerugian pelanggan) dengan nilai rata-rata sebesar 3.62. Dari data tersebut dapat disimpulkan bahwa pelanggan yang melakukan komplain pada OYO di Kota Medan lebih banyak menyatakan setuju terhadap pernyataan ke-3 variabel service recovery $(Z)$. Hal ini disebabkan oleh pelanggan yang merasa OYO telah memperhitungkan kerugian pelanggan dan memberikan kompensasi yang layak sesuai dengan kerugian pelanggan. Variabel kepuasan pelanggan (Y) pada pernyataan ke-1 (OYO memberikan pelayanan yang sesuai dengan ekspektasi/ harapan pelanggan) dengan nilai rata-rata sebesar 3.44. Dari data tersebut dapat disimpulkan bahwa pelanggan yang melakukan komplain pada OYO di Kota Medan lebih banyak menyatakan setuju terhadap pernyataan ke-1 variabel kepuasan pelanggan (Y). Hal ini disebabkan pelanggan yang merasa OYO menerapkan standar pelayanan dengan baik terhadap pelanggan untuk meminimalisir kegagalan layanan dan mencoba untuk selalu memenuhi ekspetkasi pelanggan.

\section{Analisis Jalur (Path Analysis)}

Metode analisis yang digunakan dalam penelitian ini adalah analisis jalur (path analysis). Analisis jalur digunakan untuk melakukan uji signifikansi pengaruh tidak langsung variabel Service Failure (X) terhadap variabel Kepuasan Pelanggan (Y) melalui variabel Service Recovery (Z).

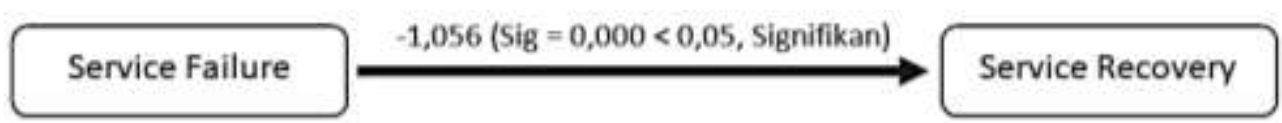

Gambar 2 : Analisis Jalur (Path Analysis) Struktur I Sumber: Data diolah 2020

Berdasarkan hasil analisis jalur (path analysis) struktur I, diketahui bahwa nilai koefisien jalur variabel Service Failure (X) terhadap variabel Service Recovery (Z) adalah 1,056. Nilai koefisien jalur bernilai negatif, yang berarti variabel Service Failure (X) berpengaruh negatif terhadap variabel Service Recovery (Z). Dengan kata lain, ketika nilai variabel Service Failure (X) yang semakin tinggi, maka nilai Service Recovery (Z) akan cenderung turun. Diketahui nilai Sig dari Service Failure 0,000 $<0,05$ dan nilai statistik t (t hitung) $|-4,592|>t$ tabel $|1,97|$, maka disimpulkan Service Failure berpengaruh negatif dan signifikan terhadap Service Recovery. 
INOBIS: Jurnal Inovasi Bisnis dan Manajemen Indonesia Volume 02, Nomor 02, Maret 2019

Muhammad Hajar Haitami, Syafrizal Helmi Situmorang

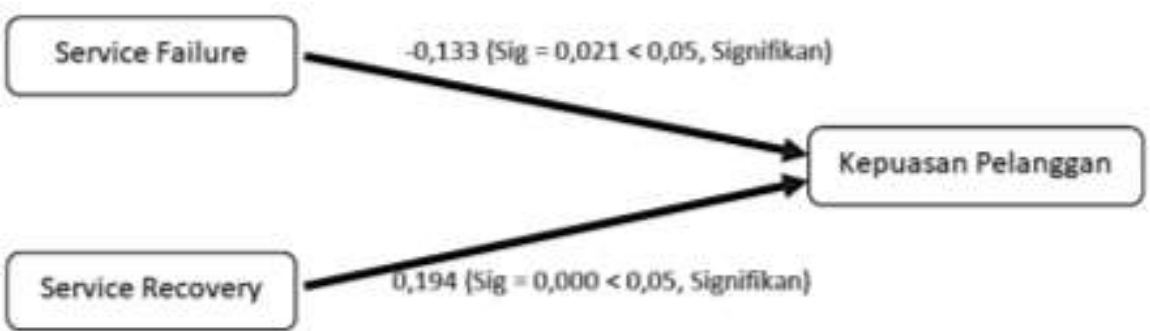

Gambar 3 : Analisis Jalur (Path Analysis) Struktur II Sumber: Data diolah 2020

Berdasarkan hasil analisis jalur (path analysis) struktur II, diketahui bahwa nilai koefisien jalur variabel Service Failure (X) terhadap variabel Kepuasan Pelanggan (Y) adalah -0,133. Nilai koefisien jalur bernilai negatif, yang berarti variabel Service Failure (X) berpengaruh negatif terhadap variabel Kepuasan Pelanggan (Y). Dengan kata lain, ketika nilai Service Failure yang semakin tinggi, maka nilai Kepuasan Pelanggan semakin rendah. Diketahui nilai Sig dari variabel Service Failure adalah 0,021 $<0,05$ dan nilai statistik t (t hitung) $|-2,330|>t$ tabel 1,97, maka dapat disimpulkan bahwa Service Failure berpengaruh negatif dan signifikan terhadap Kepuasan Pelanggan.

Diketahui nilai koefisien jalur variabel Service Recovery (Z) terhadap variabel Kepuasan Pelanggan (Y) adalah 0,194. Nilai koefisien jalur bernilai positif, yang berarti variabel Service Recovery berpengaruh positif terhadap variabel Kepuasan Pelanggan (Y). Dengan kata lain, ketika nilai Service Recovery yang semakin tinggi, maka nilai Kepuasan Pelanggan juga akan semakin tinggi. Diketahui nilai Sig dari Service Recovery adalah 0,000 < 0,05 dan nilai statistik $\mathrm{t}$ ( $\mathrm{t}$ hitung) $|10,195|>\mathrm{t}$ tabel 1,97, maka dapat disimpulkan bahwa Service Recovery berpengaruh positif dan signifikan terhadap Kepuasan Pelanggan.

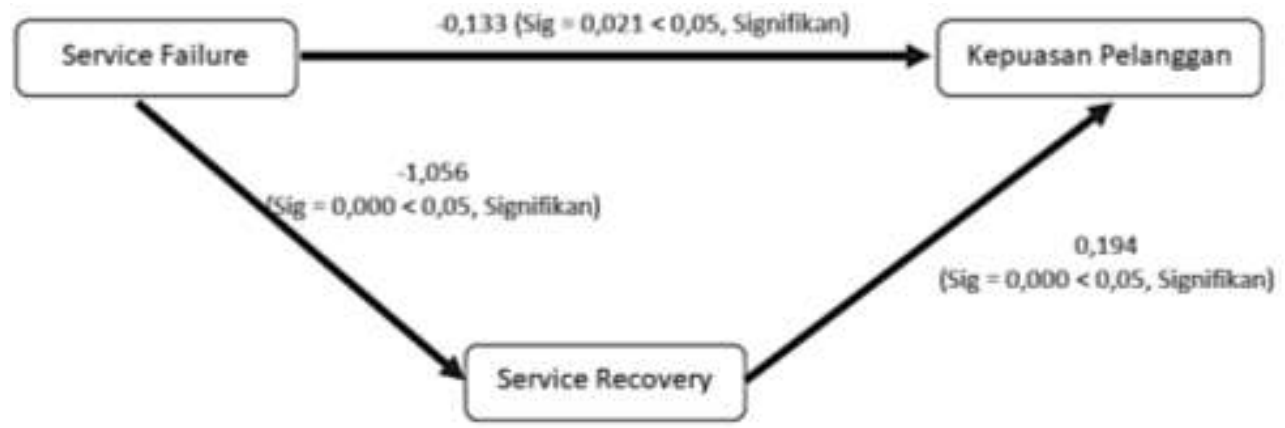

Gambar 4. Pengujian Mediasi

Berdasarkan hasil pengujian mediasi pada Gambar 4, diketahui pengaruh langsung Service Failure terhadap Service Recovery adalah -1,056. Sementara pengaruh langsung Service Recovery terhadap Kepuasan Pelanggan adalah 0,194. Sehingga pengaruh tidak langsung Service Failure terhadap Kepuasan Pelanggan, melalui Service Recovery sebesar 1,056 x 0,194 = -0,204. Diketahui Service Failure berpengaruh signifikan terhadap Service Recovery dan juga Service Recovery berpengaruh signifikan terhadap Kepuasan Pelanggan, sehingga dapat disimpulkan bahwa Service Recovery signifikan memediasi hubungan antara Service Failure terhadap Kepuasan Pelanggan. Dengan kata lain, Service Failure secara tidak langsung signifikan mempengaruhi Kepuasan Pelanggan, melalui Service Recovery. 
Muhammad Hajar Haitami, Syafrizal Helmi Situmorang

\section{Pembahasan \\ Pengaruh Service Failure Terhadap Kepuasan Pelanggan Pada Pelanggan OYO di Kota Medan}

Diketahui nilai koefisien dari variabel service failure adalah -0,133, yakni bernilai negatif, yang berarti memiliki hubungan yang negatif terhadap kepuasan pelanggan. Jika variabel service failure naik sebesar satu satuan, maka kepuasan pelanggan OYO di Kota medan akan menurun sebesar -0,133. Dalam hal ini menunjukkan bahwa service failure mampu menurunkan tingkat kepuasan pelanggan. Dengan kata lain, ketika nilai service failure yang semakin tinggi, maka nilai kepuasan pelanggan semakin rendah.

Hasil analisis jalur (path analysys) dalam penelitian ini menunjukkan bahwa service failure berpengaruh signifikan terhadap kepuasan pelanggan. Hal ini dibuktikan dengan melihat tabel analisis jalur (path analysis). Pada tabel tersebut diperoleh nilai signifikansi sebesar 0,021 yang mana lebih kecil dari 0,05. Kemudian diketahui nilai statistik t (t hitung) adalah $|-2,330|>\mathrm{t}$ tabel $|1,97|$ yang menunjukkan bahwa variabel service failure memiliki hubungan signifikan terhadap kepuasan pelanggan.

Hal ini dapat dibuktikan sesuai dengan jawaban yang di dapat dari kuesioner yang telah disebar dimana memperlihatkan bahwa sebanyak 39 orang responden atau $26 \%$ responden menyetujui tentang pernyataan "OYO membuat janji yang berlebihan dalam hal fasilitas sehingga tidak sesuai dengan ekspetasi pelanggan”. Artinya bahwa fasilitas yang ditawarkan oleh OYO memiliki kualitas yang tidak sesuai dengan yang diberikan. Pelanggan sangat sensitif dengan service failure, apabila pelanggan menemukan service failure seperti fasilitas yang di tawarkan OYO tidak sesuai ekspetasi, maka kemungkinan besar pelanggan akan beralih ke kompetitor sejenis. Tetapi tidak semua pelanggan OYO mengalami service failure. Melainkan banyak juga pelanggan yang mendapatkan fasilitas yang sesuai dengan apa yang ditawarkan oleh OYO dan mendapatkan kualitas pelayanan yang baik oleh karyawan OYO karena pelayanan memang sangat bergantung pada siapa/individu yang membuatnya. Solusi untuk OYO adalah menerapkan standar pelayanan kepada seluruh mitranya dengan pengawasan yang dilakukan secara intensif, OYO harus memberikan jaminan kepada pelanggan apabila terjadi service failure ketika menggunakan layanannya dan membuat komplain pelanggan terhadap service failure yang telah terjadi menjadi sumber acuan sehingga tidak terjadi service failure yang sama.

Hasil ini menunjukan bahwa service failure mempengaruhi kepuasan pelanggan pada pelanggan OYO di Kota Medan. Artinya semakin besar service failure seperti fasilitias yang ditawarkan tidak sesuai dengan ekspetasi pelanggan, maka akan berpengaruh negatif terhadap perusahaan dan menurunkan tingkat kepuasan pelanggan. Pada penelitian yang telah dilakukan dapat dijelaskan bahwa telah terjadi service failure pada pelanggan OYO di Kota Medan. Pelanggan merasa fasilitas yang dijanjikan oleh OYO tidak sesuai, pelayanan yang kurang baik dilakukan oleh karyawan OYO seperti bersikap cuek, tidak sopan dll dan pelanggan lain yang membuat keributan di OYO sehingga mengganggu kenyamanan pelanggan lainnya.

Hasil penelitian ini sesuai dengan penelitian yang dilakukan oleh Prakoso et al (2020) yang menyatakan bahwa jika terjadi kegagalan pelayanan sehingga perceived performance tidak sesuai ekspetasi, maka pelanggan akan tidak puas. 


\section{Pengaruh Service Failure Terhadap Service Recovery Pada Pelanggan OYO di Kota Medan}

Diketahui nilai koefisien dari variabel service failure adalah -0,156, yakni bernilai negatif, yang berarti memiliki hubungan yang negatif terhadap service recovery. Jika variabel service failure naik sebesar satu satuan, maka service recovery pada pelanggan OYO di Kota medan akan menurun sebesar -0,156. Dalam hal ini menunjukkan bahwa service failure mampu menurunkan tingkat service recovery. Dengan kata lain, ketika nilai service failure yang semakin tinggi, maka nilai service recovery semakin rendah.

Hasil analisis jalur (path analysis) dalam penelitian ini menunjukkan bahwa service failure berpengaruh signifikan terhadap service recovery. Hal ini dibuktikan dengan melihat tabel analisis jalur (path analysis). Pada tabel tersebut diperoleh nilai signifikansi sebesar 0,021 yang mana lebih kecil dari 0,05. Kemudian diketahui nilai statistik t (t hitung) adalah |$4,592 \mid>\mathrm{t}$ tabel $|1,97|$ yang menunjukkan bahwa variabel service failure memiliki hubungan signifikan terhadap service recovery.

Hal ini dapat dibuktikan sesuai dengan jawaban yang di dapat dari kuesioner yang telah disebar dimana memperlihatkan bahwa sebanyak 31 orang responden atau 20,67\% responden tidak setuju tentang pernyataan "OYO memberikan solusi sesuai dengan yang dibutuhkan pelanggan". Artinya bahwa solusi yang diberikan OYO tidak sesuai dengan apa yang dibutuhkan oleh pelanggan. Hal ini dapat disebabkan oleh service failure yang sering terjadi pada OYO namun tidak dijadikan bahan evaluasi sehingga kesulitan melakukan tindakan service recovery yang optimal. Tetapi tidak semua pelanggan OYO mengalami service failure. Melainkan banyak juga pelanggan yang mendapatkan penanganan keluhan sesuai dengan apa yang dibutuhkan. Solusi untuk OYO adalah memberikan penanganan keluhan dengan cepat dan sesuai dengan apa yang dibutuhkan oleh pelanggan serta meminimalisir terjadinya service failure yang kompleks.

Hasil ini menunjukan bahwa service failure mempengaruhi service recovery pada pelanggan OYO di Kota Medan. Artinya semakin besar service failure seperti fasilitias yang ditawarkan tidak sesuai dengan ekspetasi pelanggan, maka akan berpengaruh negatif terhadap perusahaan dan menurunkan tingkat keberhasilan service recovery. Dan pada penelitian yang telah dilakukan dapat dijelaskan bahwa telah terjadi service failure pada pelanggan OYO di Kota Medan. Pelanggan merasa fasilitas yang dijanjikan oleh OYO tidak sesuai, pelayanan yang kurang baik dilakukan oleh karyawan OYO seperti bersikap cuek, tidak sopan dll dan kurang menghargai pelanggan ketika menyampaikan keluhan.

Hasil penelitian ini didukung oleh penelitian sebelumnya yang dilakukan oleh Liestyana (2009) yang menyatakan bahwa jika service failure terjadi maka sangat penting untuk melakukan service recovery secara efektif untuk menghilangkan ketidakpuasan dan sebagai respon terhadap kualitas pelayanan yang buruk.

\section{Pengaruh Service Recovery Terhadap Kepuasan Pelanggan Pada Pelanggan OYO di Kota Medan}

Diketahui nilai koefisien dari variabel service recovery adalah 0,194, yakni bernilai positif, yang berarti memiliki hubungan yang positif terhadap kepuasan pelanggan. Jika variabel service recovery naik sebesar satu satuan, maka kepuasan pelanggan pada pelanggan OYO di Kota medan akan meningkat sebesar 0,194. Dalam hal ini menunjukkan bahwa service recovery mampu meningkatkan kepuasan pelanggan. Dengan kata lain, ketika nilai service recovery yang semakin tinggi, maka nilai kepuasan pelanggan akan semakin tinggi.

Hasil analisis jalur (path analysis) dalam penelitian ini menunjukkan bahwa service recovery berpengaruh signifikan terhadap kepuasan pelanggan. Hal ini dibuktikan dengan 
melihat tabel analisis jalur (path analysis). Pada tabel tersebut diperoleh nilai signifikansi sebesar 0,000 yang mana lebih kecil dari 0,05. Kemudian diketahui nilai statistik t (t hitung) adalah $|10,195|>\mathrm{t}$ tabel $|1,97|$ yang menunjukkan bahwa variabel service recovery memiliki hubungan signifikan terhadap kepuasan pelanggan.

Hal ini dapat dibuktikan sesuai dengan jawaban yang di dapat dari kuesioner yang telah disebar dimana memperlihatkan bahwa sebanyak 46 orang responden atau 30,67\% responden setuju tentang pernyataan "OYO mempermudah akses kepada pelanggan untuk menyampaikan keluhan". Artinya bahwa OYO telah menerapkan prosedur yang mudah dan jelas kepada pelanggan untuk menyampaikan keluhan sehinga pelanggan merasa puas.

Kemudian juga ada respon pada pernyataan "OYO memberikan keputusan yang tepat terhadap setiap keluhan" memperlihatkan bahwa sebanyak 28 responden atau 18,67\% responden tidak setuju. Artinya bahwa terdapat service recovery yang tidak maksimal seperti tidak memberikan keputusan yang tepat dalam menangani keluhan pelanggan. Hal ini dapat terjadi ketika terdapat service failure dan pihak OYO tidak memahami apa yang terjadi dan memberikan keputusan yang tidak tepat sehingga pelanggan merasa dirugikan. Tetapi tidak semua pelanggan OYO mengalami service recovery yang tidak maksimal. Melainkan banyak juga pelanggan yang mendapatkan service recovery dengan cepat dan sesuai dengan apa yang dibutuhkan pelanggan. Solusi untuk OYO adalah mendengarkan dan mencoba memahami service recovery yang disampaikan pelanggan, lalu membuat keputusan berdasarkan fakta yang terjadi dan memberikan kompensasi yang sesuai dengan kerugian pelanggan.

Hasil ini menunjukan bahwa service recovery mempengaruhi kepuasan pelanggan pada pelanggan OYO di Kota Medan. Artinya semakin besar service recovery seperti mempermudah akses kepada pelanggan untuk menyampaikan keluhan dan memberikan keputusan yang tepat terhadap keluhan tersebut, maka akan berpengaruh positif terhadap perusahaan dan meningkatkan kepuasan pelanggan. Dan pada penelitian yang telah dilakukan dapat dijelaskan bahwa OYO telah melakukan service recovery pada pelanggan OYO di Kota Medan. Pelanggan merasa OYO memberikan kemudahan akses dalam penyampaian keluhan dan OYO menghargai pelanggan ketika menyampaikan keluhan.

Hasil penelitian ini sesuai dengan penelitian yang dilakukan oleh Adhitya dan Rahanatha (2015) yang menyatakan bahwa service recovery berpengaruh positif dan signifikan terhadap kepuasan pelanggan hotel.

\section{Pengaruh Service Failure Terhadap Kepuasan Pelanggan Melalui Service Recovery Pada Pelanggan OYO di Kota Medan}

Diketahui pengaruh langsung service failure terhadap service Recovery adalah -1,056. Sementara pengaruh langsung service recovery terhadap kepuasan pelanggan adalah 0,194. Sehingga pengaruh tidak langsung service failure terhadap kepuasan pelanggan, melalui service recovery sebesar $-1,056$ x $0,194=-0,204$. Diketahui service failure berpengaruh signifikan terhadap service recovery dan juga service recovery berpengaruh signifikan terhadap kepuasan pelanggan, sehingga dapat disimpulkan bahwa service recovery signifikan memediasi hubungan antara service failure terhadap kepuasan pelanggan. Dengan kata lain, service failure secara tidak langsung signifikan mempengaruhi kepuasan pelanggan, melalui service recovery.

Hal ini dapat dibuktikan sesuai dengan jawaban yang di dapat dari kuesioner yang telah disebar dimana memperlihatkan bahwa sebanyak 43 orang responden atau $28,67 \%$ responden setuju tentang pernyataan "pelanggan tetap memiliki harapan/ekspetasi terhadap OYO walaupun ada kemungkinan terjadi kegagalan layanan kembali". Artinya bahwa pelanggan tetap menggunakan layanan OYO walaupun pernah terjadi service failure. Hal ini 
dapat disebabkan oleh service recovery yang cukup optimal dilakukan oleh OYO sehingga mengembalikan kepuasan pelanggan setelah mengalami service failure. Hasil ini menunjukan bahwa service failure mempengaruhi kepuasan pelanggan melalui service recovery pada pelanggan OYO di Kota Medan. Artinya semakin besar service recovery seperti mempermudah akses kepada pelanggan untuk menyampaikan keluhan dan memberikan keputusan yang tepat terhadap keluhan tersebut, maka akan berpengaruh positif terhadap perusahaan dan meningkatkan kepuasan pelanggan.

Hasil penelitian ini sesuai dengan penelitian yang dilakukan oleh Putri et al (2019) yang yang menyatakan bahwa service recovery memiliki kecenderungan mempengaruhi customer satisfaction.

\section{Kesimpulan dan Saran}

\section{Kesimpulan}

1. Berdasarkan hasil analisis jalur (path analysis) struktur II, diketahui bahwa nilai koefisien jalur variabel Service Failure (X) terhadap variabel Kepuasan Pelanggan (Y) adalah -0,133. Nilai koefisien jalur bernilai negatif, yang berarti variabel Service Failure (X) berpengaruh negatif terhadap variabel Kepuasan Pelanggan (Y). Dengan kata lain, ketika nilai Service Failure yang semakin tinggi, maka nilai Kepuasan Pelanggan semakin rendah. Diketahui nilai Sig dari variabel Service Failure adalah $0,021<0,05$ dan nilai statistik $\mathrm{t}$ (t hitung) $|-2,330|>\mathrm{t}$ tabel 1,97 , maka dapat disimpulkan bahwa Service Failure berpengaruh negatif dan signifikan terhadap Kepuasan Pelanggan.

2. Berdasarkan hasil analisis jalur (path analysis) struktur I, diketahui bahwa nilai koefisien jalur variabel Service Failure $(\mathrm{X})$ terhadap variabel Service Recovery $(\mathrm{Z})$ adalah -1,056. Nilai koefisien jalur bernilai negatif, yang berarti variabel Service Failure (X) berpengaruh negatif terhadap variabel Service Recovery (Z). Dengan kata lain, ketika nilai variabel Service Failure (X) yang semakin tinggi, maka nilai Service Recovery (Z) akan cenderung turun. Diketahui nilai Sig dari Service Failure 0,000< 0,05 dan nilai statistik t (t hitung) $|-4,592|>t$ tabel |1,97|, maka disimpulkan Service Failure berpengaruh negatif dan signifikan terhadap Service Recovery.

3. Diketahui nilai koefisien jalur variabel Service Recovery (Z) terhadap variabel Kepuasan Pelanggan (Y) adalah 0,194. Nilai koefisien jalur bernilai positif, yang berarti variabel Service Recovery berpengaruh positif terhadap variabel Kepuasan Pelanggan (Y). Dengan kata lain, ketika nilai Service Recovery yang semakin tinggi, maka nilai Kepuasan Pelanggan juga akan semakin tinggi. Diketahui nilai Sig dari Service Recovery adalah $0,000<0,05$ dan nilai statistik t (t hitung) $|10,195|>t$ tabel 1,97, maka dapat disimpulkan bahwa Service Recovery berpengaruh positif dan signifikan terhadap Kepuasan Pelanggan.

4. Berdasarkan hasil pengujian mediasi pada Gambar 4.5, diketahui pengaruh langsung Service Failure terhadap Service Recovery adalah -1,056. Sementara pengaruh langsung Service Recovery terhadap Kepuasan Pelanggan adalah 0,194. Sehingga pengaruh tidak langsung Service Failure terhadap Kepuasan Pelanggan, melalui Service Recovery sebesar $-1,056$ x 0,194 = -0,204. Diketahui Service Failure berpengaruh signifikan terhadap Service Recovery dan juga Service Recovery berpengaruh signifikan terhadap Kepuasan Pelanggan, sehingga dapat disimpulkan bahwa Service Recovery signifikan memediasi hubungan antara Service Failure 
terhadap Kepuasan Pelanggan. Dengan kata lain, Service Failure secara tidak langsung signifikan mempengaruhi Kepuasan Pelanggan, melalui Service Recovery.

5. Diketahui nilai F hitung 72,057 dan nilai Sig. adalah 0,000. Maka nilai F tabel dengan df $1=2$, df $2=147$ dan tingkat signifikansi 5\% atau 0,05 adalah 3,057. Diketahui nilai F hitung 72,057 > F tabel 3,057 dan nilai Sig adalah 0,000 <0,05, maka Service Failure dan Service Recovery secara bersama-sama atau serempak berpengaruh signifikan terhadap Keputusan Pelanggan.

\section{Saran}

1. Bagi Perusahaan PT OYO Rooms Indonesia

a. Melakukan evaluasi secara rutin terhadap service failure yang terjadi dan menjadikan pembelejaran untuk tidak terjadi service failure yang sama kedepannya khususnya terhadap permasalahan kamar, menerapkan standar kualitas layanan dan fasilitias kepada seluruh mitra OYO di Indonesia serta memberikan jaminan kepada pelanggan OYO agar pelanggan tidak merasa cemas ketika terjadi service failure.

b. OYO juga harus dapat memberikan sanksi yang tegas terhadap mitranya apabila tidak mengikuti standar pelayanan yang terlah ditetapkan agar dapat meminimalisir terjadinya service failure.

c. Pihak OYO lebih mencermati keluhan yang disampaikan oleh pelanggan dan bersungguh-sungguh dalam mencari solusi yang berujung kepada keputusan yang tidak merugikan pihak manapun.

d. Menjadikan kegagalan layanan yang terjadi sebagai keuntungan untuk memperbaiki layanan dan memberikan pemulihan layanan yang baik seperti kompensasi yang wajar dan proses yang cepat sehingga diharapkan service recovery dapat menciptakan kepuasan pelanggan pasca terjadi service failure.

2 Untuk peneliti selanjutnya

a. Diharapkan penelitian berikutnya tidak sebatas variabel service failure, service recovery dan kepuasan pelanggan tetapi juga menambahkan variabel lain seperti WOM dan loyalitas pelanggan pada penelitian selanjutnya.

b. Perlunya ditambah faktor-faktor yang mempengaruhi kepuasan pelanggan seperti kualitas layanan dan harga. Hal ini bertujuan untuk semakin menyempurnakan pemahaman terhadap faktor-faktor yang mempengaruhi kepuasan pelanggan.

\section{Daftar Pustaka}

Armstrong, Kotler 2015, “Marketing an Introducing Prentice Hall twelfth edition”, England : Pearson Education, Inc.

Adhitya, C \& Rahanatha, B. (2015). ANALISIS PENGARUH PEMULIHAN PELAYANAN TERHADAP KEPUASAN PELANGGAN PADA HOTEL TJAMPUHAN UBUD.

Fatricia, R., \& Priadi, E., (2018). THE EFFECT OF SERVICE RECOVERY ON SPEEDY'S CUSTOMER SATISFACTION.

Gunawan, E., et al (2019). ANALISA PENGARUH KUALITAS LAYANAN TERHADAP KEPUASAN PELANGGAN MENGINAP DI EMPAT VIRTUAL HOTEL OPERATOR DI SURABAYA. 
Hair, Joseph F., et.al. (2013). Multivariate Data Analysis, 8th Edition. New York: Prentice Hall International, Inc.

IDN Research (2019). Indonesian Millenials Report 2019.

Koc, E. (2017). Service Failures and Recovery in Tourism and Hospitality: A Practical Manual.

Kotler, P., \& Keller, K. L. (2016). Marketing Management. England.

Lovelock, C. H., \& Wirtz, J. (2018). Essentials of Service Marketing. London.

Liestyana, Y. (2009). PERSEPSI NASABAH TENTANG LAYANAN PERBANKAN: PENGARUH SERVICE FAILURE DAN STRATEGI SERVICE RECOVERY TERHADAP BEHAVIORAL INTENTIONS.

Prakoso, P., S., et al (2020). THE EFFECT OF WORK SYSTEMS AND SERVICE QUALITY TOWARD GUEST SATISFACTION AT FRONT OFFICE DEPARTMENT IN BWALK HOTEL, DAU, MALANG.

Putri, Luccy A., R., et al (2019). Pengaruh Service Recovery Terhadap Customer Satisfaction Pada Hotel Royal Jember.

Situmorang, S. H., \& Mulyono, H. (2019). Service Marketing. Medan.

Sugiyono. (2017). Metodologi Penelitian Bisnis (Pendekatan Kuantitatif Kualitatif dan $R$ \& $D)$. Bandung: Alfabeta. 